\title{
The Status of Women in the Accounting Profession in Jordan: An Exploratory Study
}

\author{
Rasha Qasem ${ }^{1} \&$ Modar Abdullatif ${ }^{2}$ \\ ${ }^{1}$ Al-Montaser Technical Services, Amman, Jordan \\ ${ }^{2}$ Department of Accounting and Finance, Faculty of Business, Middle East University, Amman, Jordan \\ Correspondence: Modar Abdullatif, Department of Accounting and Finance, Faculty of Business, Middle East \\ University, P. O. Box 383, Amman 11831, Jordan. Tel: 962-79-672-6101. E-mail: mod70a@yahoo.com
}

Received: June 7, 2014

Accepted: June 23, 2014

Online Published: July 25, 2014

doi:10.5539/ibr.v7n8p146

URL: http://dx.doi.org/10.5539/ibr.v7n8p146

\begin{abstract}
This study aimed at exploring the status of women in the accounting profession in Jordan by analysing the differences between males and females working in accounting-related jobs in Jordan in terms of their personal characteristics and the effects of workplace conditions on them, and what these factors may have on pay levels and job progress for both sexes. The study also aimed to compare the status of women in accounting-related jobs in Jordan with that in developed countries. To achieve that, the study used semi-structured interviews with 31 individuals (men and women) who work in accounting-related jobs (such as accounting, financial management, internal auditing, and external auditing). The content of the interviews was analysed using thematic analysis.

Findings showed differences between men and women in accounting-related jobs in Jordan due to the nature of the individual and to the Jordanian culture and the adaptation to the conditions of the workplace. These differences were found to have an effect on the pay levels and job progress of both sexes, with some discrimination against females on these issues. Despite being an international phenomenon, discrimination against women in accounting-related jobs was found to be larger in Jordan than in developed countries due to the characteristics of the Jordanian society and culture and the characteristics of the Jordanian workplace.
\end{abstract}

Keywords: women/females, accounting profession, personal characteristics, workplace conditions, Jordan

\section{Introduction}

Despite the enacting of numerous regulations worldwide concerning gender issues, and the establishment of numerous associations committed to women rights in the workplace, the application of such regulations in practice has been limited, even in more-developed countries. In the particular area of the accounting profession, several studies were undertaken to analyse the relatively low number of women in the professional accounting industry who have advanced in their career and positions (see Whiting \& Wright, 2001; Broadbent \& Kirkham, 2008; Dambrin \& Lambert, 2008; Kornberger, Carter \& Ross-Smith, 2010). While there are arguments that this difference in numbers is somewhat decreasing (Dambrin and Lambert, 2012), the likelihood of gender discrimination still largely exists. Given that, the researchers aimed to study gender issues in the accounting profession in Jordan and find whether there is an existence of any professional discrimination that is shown through the salaries or promotion opportunities between female and male Jordanian accountants. Since Jordan is a relatively conservative context, expected by some to have a relatively larger gender gap, compared to less-conservative, more-developed contexts (Yeganeh \& May, 2011), it makes a potentially interesting environment to study gender issues in the accounting profession in, and compare these to what exists in more-developed countries.

This study emphasises the nature of the differences between male and female workers in accounting-related jobs in Jordan in terms of personal characteristics and work characteristics, and how would this impact their job prospects, and whether this will cause discrimination against women, especially in the areas of pay and job progress.

The main research questions this study aims to answer are:

1) How do personal characteristics (such as competitiveness, decisiveness, leadership ability, desire for responsibility, ability to handle pressure, and career aspirations) differ between males and females in 
accounting-related jobs in Jordan?

2) How do workplace conditions (such as qualifications, work experience, number of working hours, effect of family responsibilities, and mobility) differ between males and females in accounting-related jobs in Jordan?

3) What impact may personal and workplace characteristics have on females working in accounting-related jobs (such as accounting and financial management and auditing)? And could these factors lead to discrimination between males and females in terms of payment and job progress?

4) Could the findings of this research be attributed to special characteristics of the Jordanian context, and how do they differ from findings of similar research in more-developed countries?

\section{Literature Review}

\subsection{Women in the Accounting Profession}

Inequality between females and males in accounting-related jobs is considered an international phenomenon. In 1940, there were about 16000 CPAs in the USA, of whom only 175 were women (Wootton \& Spruill, 1994). Many companies hired female accountants as secretaries, with Arthur Andersen hiring its first female staff accountant in 1965 (Wootton \& Spruill, 1994). Female students of accounting increased rapidly through the following years, and they started to occupy different positions, rather than being merely secretaries or bookkeepers.

Generally, women face several challenges based on the social culture and traditions reflected through their families and colleagues. The accounting sector was generally perceived as being complicated, tough and masculine, an issue that motivated women to choose other majors for academic studies, and resulted in a low share for women in accounting jobs. Some female accountants experience discrimination by being moved to another department or being rejected because of their lack of sufficient confidence, or just being told that they are not wanted because they have children and may therefore ask for leaves and vacations (Lord \& Robb, 2010). Female accountants also face more obstacles than men, as shown by discrimination in salaries and promotions, even if they had the same qualifications (Fasci \& Valdez, 1998). American audit firms noticed that although over $50 \%$ of accounting graduates were women in 1991, their share in accounting jobs at entry level was relatively low, and they did not advance quickly and had high turnover because of salaries and dissatisfaction at the work environment (Reed, Kratchman \& Strawser, 1994). Even in the less-developed country context of Botswana, Kumar (2010) found that numbers of female accounting graduates entering the profession are more than those of males, but males largely tend to occupy the higher managerial positions and earn more than females.

Irish female accountants faced discrimination for several reasons, such as refusal of men to work under female managers and taking orders from them, and were crowded in jobs with low salaries (Brennan \& Nolan, 1998). Whiting and Wright (2001) surveyed views of accountants in New Zealand, and found that female accountants were paid less and held a lower job status than their male colleagues because of gender discriminations and letting women have less working hours. Broadbent and Kirkham (2008) concluded that despite the development through the previous years, opportunities for female accountants in professional and even academic roles face obstacles that limit their progress.

Females are likely to face conflicts while trying to balance their work tasks and their family responsibilities, thus causing them to leave their jobs even if they have the needed skills and experience to be promoted and get high positions (Fogarty, 1996). Particularly, audit job requirements and pressure causes stress that affects women more than men (Collins, 1993). In a study in two Big Four audit firms in France, Dambrin and Lambert, (2008) found that there was gender balance at the entry level, but the gender gap showed a significant difference through the upper levels in the firms because of the obstacles that women faced during their progress, especially when they had to balance their career development and their childcare responsibilities.

The late entrance of women into the accounting industry caused a lack in the number of them in leadership positions. However, some studies found that characteristics of women, especially under stress or when facing risk (where they might lack sufficient confidence), or their lifestyle choice which focuses on family responsibilities at home make a good explanation for the gap between men and women working in accounting firms (Dambrin \& Lambert, 2012). Male management behaviour and females' lack of training caused a low participation of women in high positions. This is exacerbated by the societal culture which raises girls to accept the orders and boys to issue them, thus suggesting that management is a role only for males, not for females. (Zubaidi, Al-sammerai \& Ahmad, 2011). 
Dambrin and Lambert (2012) performed a reflexive analysis of a large number of research papers on the topic of the rarity of women in high accounting-related positions. They report that while some studies have argued that it is just a matter of time until women occupying top accounting positions will increase (see Davidson \& Dalby, 1993; French \& Meredith, 1994), other studies have concluded that women are less in top accounting-related positions due to their different personal characteristics (see Reed et al., 1994) or the family-centred lifestyle (see Bernardi, 1998). Working conditions in the profession were also offered as an explanation for the rarity of women in top accounting related positions (see Barker \& Monks, 1998).

In the only study in Jordan to emphasise the accounting sector (according to the researchers' best knowledge), Abed and Al-badainah (2013) examined the relationship between gender and payment level for auditors in Jordan by interviewing ten Jordanian auditors (five males and five females). They found that there is no impact of gender on the payment level. Moreover, they found that women are more committed to their jobs. They noticed that when they interviewed female auditors, the auditors had a male monitor with them and were looking at the monitors before answering any question, despite both of the interviewers being females.

The main difference between this study and previous studies is that previous studies in foreign countries covered gender issues in contexts having significantly different characteristics than those of the Jordanian context. On the other hand, there are Jordanian studies that covered gender issues in general but, to the researchers' best knowledge, no single study covered issues regarding gender in the accounting profession in Jordan to the detail this study did. This study has the potential for a significant contribution to knowledge in this area regarding Jordan in particular, and relatively similar Arab and other developing countries in general.

\subsection{Theories on Gender Issues in the Workplace}

There are several feminist theories referred to in the literature. Two of these theories are interpersonal behaviour and structure. According to Eitzen, Zinn and Smith (2010), interpersonal behaviour theory deals with character differences between males and females and how that may affect their behaviour. It is argued that males make direct, sometimes aggressive, decisions and have high confidence. On the other hand, females tend to negotiate and consult others, are committed to family responsibilities, and take conservative decisions. This is a possible interpretation of why males are more likely to occupy leadership positions in organisations, compared to females.

According to Whiting and Wright (2001), structure theory argues about the effects of the structures of the workplace on female inequality through organisation conditions, such as salaries, evaluation, training and other benefits. A suggested explanation for that may be the role of the mentor, since male mentors are arguably more helpful to their male colleagues through networking inside and outside the workplace, while their female colleagues cannot join them and negotiate work issues and share their views. This issue increases in prevalence in high positions, where it is less likely to have female mentors (Whiting \& Wright, 2001).

Personal and social factors potentially affect the movement of professional female and male accountants in their career paths. These include self confidence, leadership skills, the ability to handle the required responsibilities, and dependent children and elderly family members which may restrict the mobility, etc (Whiting \& Wright, 2001). This study therefore attempts to explore the effects of personal characteristics and workplace conditions on the job prospects of females in Jordan, and discusses the results taking into account the characteristics of the Jordanian context.

Various studies (such as Whiting \& Wright, 2001; Dambrin \& Lambert, 2008; Komori, 2008; Kumar, 2010; Dambrin \& Lambert, 2012) have suggested that if there is inequality in treatment between females and males in the workplace, it will mainly be caused by personal characteristics and/or workplace conditions. Personal characteristics mean the natural differences between females and males in general and how these differences affect their work in accounting-related jobs. These attributes include decisiveness in decision making, leadership ability, career aspirations and desire for responsibility, ability to handle pressure and high volume workloads, commitment to quality and adaptation to change. As for workplace conditions, there are various factors that are involved in the work environment and may cause inequality between females and males in accounting-related jobs. These include competitiveness in qualifications, competitiveness in work experience, job descriptions, effect of marital status and family responsibilities, mobility and number of working hours. These personal characteristics and workplace conditions (selected after reviewing extant literature, such as those studies listed earlier in this paragraph, among others) will be the main factors analysed in this study.

\section{Research Method}

This is an exploratory study, so in order to find about the status of women in their working places in Jordan the 
researchers used oral interviews. This is a qualitative approach that is arguably most likely to suit this type of study since the exact issues to ask are not very clear given the lack of sufficient relevant literature, especially in Jordan. The type of interview questions is semi-structured, in order to have control on the discussion, but allow the interviewee the chance to elaborate on his/her points and aid the exploratory nature of the study (Eriksson \& Kovalainen, 2008).

In order to study the status of women as accounting professionals, the research population consisted of females and males who are working in accounting-related jobs in the Jordanian private sector. These jobs generally include roles of accountants, financial managers, financial analysts, internal auditors and external auditors. The study population consisted of both males and females. This is considered as being useful since it will allow collecting views from both sexes on the status of women in Jordanian accounting-related jobs, thus allowing comparison of these views where applicable. This approach of defining the study population was preferred as it offers comparative views and eliminates to some extent the possibility of bias that may occur when only females are selected as a study population for a gender-related topic.

Initially, the researchers sought to interview about 30 individuals with at least ten years of professional accounting-related experience (some or all of it in Jordan). However, especially in the female group, the researchers found that there are very few females who meet the above mentioned condition. Therefore, the ten years minimum experience condition was relaxed to a minimum of six years in some cases for the sample of females (although six females from the sample had over ten years of professional experience). As for the sample of males, the minimum experience was nine years for one interviewee, with all of the rest having ten or more years of professional experience (eight had 20 or more years of professional experience).

The final sample consisted of 31 interviewees, of which 17 were males and 14 were females. The vast majority of these individuals had at least ten years of professional experience. 18 individuals - ten males and eight females - (about 58\% of the population) had some extent of international experience in accounting-related jobs. This means having worked outside Jordan and/or worked for an international institution in Jordan (In fact, one of the interviewees was not a Jordanian). This is important since the interview questions asked about comparing the status of women in accounting-related jobs in Jordan and in developed countries.

The interviews were conducted in 2013. They were conducted either at the interviewee's workplace or in a public place, apart from one that was conducted using Skype. All but one interview (the interviewee refused recording the interview) were recorded and later transcribed. The length of the interviews ranged from about half an hour to about 2.5 hours, depending on the time allowed by the interviewee.

Thematic analysis was used in analysing the findings. Thematic analysis is a form of analysis where "the researcher focuses analytical techniques on searching through the data for themes and patterns" (Glense, 2011, p.187). Eriksson and Kovalainen (2008, p. 309) define thematic analysis as "A form of analysis which has the theme or category as its unit of analysis, and which looks across data from many different sources to identify themes". Responses to interview questions were classified into themes for useful analysis, and quotes from individuals were added for emphasis. These patterns of causality in such an analysis approach are important in order to study social reality in a way not easily captured by quantitative variables (Ahrens \& Chapman, 2006).

The interviews included asking questions about the differences between females and males in accounting related jobs in Jordan that can be attributed to their personal characteristics or to their workplace conditions (Appendix A shows the interview questions). The personal characteristics factor included questions regarding decisiveness in decision making, leadership ability, career aspirations and desire for responsibility, ability to handle pressure and high volume workloads, commitment to quality, and adaptation to change. The workplace conditions factor included questions regarding competitiveness in qualifications, competitiveness in work experience, job descriptions, effect of marital status and family responsibilities, mobility, and number of working hours (including working during vacation). The questions also included the potential effect of the personal characteristics and workplace conditions factors on pay level and job progress, and whether there is any discrimination against females regarding that, and whether there are differences between Jordan and the developed countries related to these issues. These themes were developed by the researchers after reviewing relevant literature and consulting a small sample of individuals to review the list of questions and themes before conducting the interviews. While the theoretical background is necessary, the researchers also recognised the importance of the possible existence of other patterns that may appear from analysing the empirical data (see Ahrens \& Dent, 1998; Vaivio, 2008). However, no other significant patterns appeared when the data were analysed, so the predetermined themes were used to categorise the findings. 


\section{Findings}

While the study sample included both men and women in order to show possible differences between their views, these differences were generally not very significant, as were the differences among views from different accounting-related jobs. Therefore, the following analysis does not emphasise differences related to gender or nature of job except in a few areas where relevant. Otherwise, the discussion emphasises the general views of all interviewees, regardless of their gender or exact job.

\subsection{Personal Characteristics}

Most of the interviews reported that success in work depends more on personal characteristics and ambitions of the individual than on gender. They saw that the Jordanian culture does not have a large effect on the individual's success, and that work success depends more on the person himself/herself. However, some interviewees viewed that the Jordanian culture, society and tradition have a negative effect on females getting accounting-related jobs, compared to males. For example, one of the external auditors said that females should not work in the accounting and finance sector in general, especially in auditing. He said:

These fields are tough and pressurising, and the natural characteristics of females do not fit for such jobs, as opposed to males. Internal design, nursing and teaching are more suitable for females, while accounting-related jobs are more suitable for the males as their characteristics, both physically and mentally, are suitable for handling pressure, working for long hours, communicating with different clients (especially aggressive ones) located in different places outside Amman, and making wise decisions without being affected by emotions. If females insist to take accounting-related jobs then they should be old enough and trained to act like men and eliminate any feminine characteristics.

Most of the interviewees said that females should have the full support from their families first, and then have the support of their school and university, and finally their managers, in order for them to succeed in work and not be discriminated against. This view might be attributed to the fact that females in Jordan are generally being brought up as dependable on males, thus affecting their personality and limiting their work success.

The following discussion summarises the general views of the interviewees on specific personal characteristics and how they affect males and females in the accounting profession in Jordan.

\subsubsection{Decisiveness in Decision Making}

Most interviewees argued that decisiveness in decision making depends on personality, but some interviewees saw that males are tougher in taking decisions because the society raises men as the ones who give orders, and that men are more confident and wise in making decisions, while women are prone to involving their emotions in the decision making process.

However, a number of interviewees argued that if women have good training and if their families used to listen to their views, they can be tougher and more confident, especially when they reach high managerial positions. According to these interviewees, this phenomenon is found more in the developed countries than in Jordan, because in the developed countries, females tend not to be raised to accept the orders from monitors without discussion. It was also reported that the international and big firms are trying to reduce discrimination against females in this area through encouraging them and giving junior female staff the necessary training. However, these interviewees argued that Jordanian firms are lagging in this particular area, compared to international firms.

Examples of views that are positive about the abilities of females as decision makers include the following two quotes by female interviewees:

I was reporting to a female and admired how she was taking great and quick decisions. The clients also asked her for consulting.

Females are more confident in their decisions because they take them after studying the issue carefully and because they take care of details by nature.

Nevertheless, there were some negative cases regarding the ability of female managers to make decisions. For example, two male interviewees reported that they were reporting to a female boss that took tough decisions and asked them to follow her orders without listening to their views. They argued that most of these decisions were incorrect, and that they left their positions due to the role of the female boss.

\subsubsection{Leadership Ability}

As for leadership ability, the interviewees generally saw that both sexes are equal on that, but that the Jordanian 
society puts obstacles in the face of females, limiting their ability to show their capabilities, especially at the junior levels. However, some interviewees argued that if females achieve higher positions, such obstacles may be alleviated. A female audit partner said that according to her experience "business owners in Jordan prefer working with a high position female because of trust, as female rarely commit illegal acts, compared to males who take this risk".

Some CFOs said that while both males and females have similar leadership abilities, in the Jordanian culture males are given more opportunities, as the masculine mentality refuses to have a female managing a male. One male auditor extended this view by arguing that females are perceived as not suitable even to manage females, describing the relation between a female manager and her female subordinate as "hell". Another male interviewee said:

Generally, male accountants look to be leaders because in their culture, reporting to a female is a shame.

\subsubsection{Career Aspiration and Desire for Responsibility}

Findings generally showed that at the junior level males have a clearer vision for their career path, and this reflects how ambitious they are through asking for more responsibilities. On the other hand, at the junior level females do not have a clear vision about their career, given that they are brought up to concentrate on social stability, so they don't have a clear vision about whether they will complete their career path. Nevertheless, some interviewees argued that after females pass this first step of work they can be more focusing on their career path and taking as many responsibilities as males, depending on personal characteristics rather than gender. However, other social factors may also impact the situation of women at later stages of work. For example, according to a male CFO:

Females have big ambitions and work very hard until the moment they are engaged, then they may abandon all of their experience and leave their jobs, or if they stay working they stop taking more responsibilities and stick to the same position with its routine responsibilities, rather than take more challenging positions

On the other hand, a female in a high financial accounting position argued that:

This criterion depends more on the person him/herself, whether they are ambitious or motivated to move on and develop their career path.

The Jordanian society was reported to be more characterised by differences between males and females than those of developed countries because of the culture. A female financial manager reported refusing to take an opportunity and have a big leap in her career path because her husband told her that he is the man and the one responsible for securing the money, and in no way would he leave his position to go with her or leave her travel alone to other locations.

\subsubsection{Ability to Handle Pressure and High Volume Workloads}

Most interviewees reported that ability to handle pressure and high volume workloads is not affected by gender, as both females and males have the ability to work under pressure. However, some interviewees see that married women avoid handling heavy pressure because of having family responsibilities, and that this is the same in Jordan as is in developed countries.

In addition, some interviewees argued that females are multi-tasked and can concentrate on different tasks at the same time. To the contrary, males tend to be unable to focus on more than one task at the same time, and that means that females can handle high volumes of workloads and different responsibilities in a more efficient way, compared to males.

\subsubsection{Adaptation to Change}

Most interviewees agreed that females generally show more stability and commitment to work in their organisations. Females (especially married ones) tend not to accept better financial offers if they include being far from the home and family, needing to travel to other countries, needing for adapting to new job environments and conditions, or lacking flexibility in leaving hours (For example, if the current job allows the female to pick children up from schools). A female also does often not take the change decision by herself but asks her husband, father or brother. This is different between Jordan and more developed countries, where females are likely to be more independent and adapt to change. To the contrary, males look for better positions and better salaries and take opportunities without thinking twice.

But if the change will be at the same company then females were reported by many interviewees to be more 
flexible in taking it than males because of their nature, as they like stability at a company but do not mind changing their routine there. Females consider their workplace as their home and look for having the better practice and procedures. On the other hand, some interviewees saw that adaptation to change does not depend on gender but on age, as younger individuals from both sexes tend to adapt easier than older ones, as junior staff take training for new systems and adapt. One female CFO argued that "this depends on the manager not on the gender of the employee because as a human, one generally refuses the changes but if the manager has an open discussion with his/her staff and discusses with them the advantages of using the new polices or procedures they can suggest new ideas and feel that they are an effective part of the entity, and that the change decision is their idea. This will encourage them to do their best to implement the change".

\subsubsection{Commitment to Quality}

Most of the interviewees argued that females are more detailed and more organised, and that this helps them to provide the needed reports in more efficient ways than their male colleagues who do not have patience to do tasks but prefer to give an approximate result which sometimes by experience is accurate. Males tend not to care about the tidiness of their work and how they got the results. Most external auditors preferred, at the orientation stage, to send females (in addition to males) to clients because they find that females concentrate more on the details that sometimes are small but make a big effect, and that females do stick to the orders exactly, the fact that helps in many cases, especially in those involving fraud. Other CFOs saw that this depends on the experience and how you can rely on your subordinates regardless of their gender, and said that each manager should be a leader not a boss and give their staff the needed coaching to concentrate on their positive skills and reduce their negative ones.

\subsection{Workplace Conditions}

Findings reported that there are differences between females and males in accounting-related jobs in Jordan, and that Jordan lags behind developed countries on the workplace conditions factor. In the following subsections these differences are described in some detail.

\subsubsection{Competitiveness in Qualifications}

Generally, interviewees reported that males tend to have more qualifications for similar positions because they were brought up and told that that they are responsible to secure the money for their families. This makes them have a clearer vision about their career path and try to get more certificates to reach the aspired positions and get extra salaries. On the other hand, females are used to be raised to the values that social stability for a certain age is more important and they tend to focus on that. However, once they pass this stage (which is the age between 25-30 years) they can clearly focus on their jobs. Nevertheless, recently there are increasing numbers of females who complete their higher education and participate in professional certificate courses. They are taking their studies more seriously than males because they consider it as a challenge they have entered by their own choices, not as is the case with men, who are pushed by the society to do this in order to handle their financial responsibilities. This is evident by the higher university grades that females are getting, compared to those of males. To the contrary, in the developed countries because both females and males do not have the pressure of the society traditions, it can be seen that sometimes the number of females who are taking professional certificates is much more than that of their male colleagues.

On the other hand, some interviewees saw that in Jordan most married males are not looking for new qualifications, and if they have a good position they usually stick to it without looking for any added values because they have family commitments which sometimes stop their adventurous ambitions and they end up unable to handle the pressure. If this is true to some extent, then it can be argued that competitiveness depends on the person and how he/she is seeing himself/herself with their career path. This implies that marriage responsibilities might limit ambitions for having new certificates that need more efforts, time and money.

\subsubsection{Competitiveness in Work Experience}

Findings showed clearly that males generally have more work experience than females. This is added to males having diversification in their experience because they are more exposed and the society supports them by allowing them to travel without getting permission from their mentors and thinking about their family responsibilities. Females sometimes leave their jobs even if they have a good position because of a move or travel by their families, or because of marriage. They also take maternity leave and other types of vacations more than males, the fact that makes them less attractive to employers who cannot do with a high-ranked financial officer taking a long leave. Most of the interviewees saw that males have diversification in their experience, something rarely found in females in Jordan because of the culture that allows males to work for late hours 
without holding similar responsibilities for their children, and to go to different locations (especially in the audit sector) and make social networking after working hours with their colleagues and managers, the fact that helps to develop the male's character as a person and lets him learn from the experiences of others more than females. This issue doesn't exist to the same extent in developed countries because females are more exposed and travel more freely.

\subsubsection{Number of Working Hours (Including Working during Vacation)}

Generally, most interviewees argued that on the criterion of number of working hours, they prefer working with males. This is because accounting - related jobs have high seasons and closing times which need urgent reports at specific periods of time and that causes pressure to make the staff work for late hours. In Jordan, this cannot fit with females because of society traditions (even if there are facilities to work from home, since on some point they should be at office, especially at high level positions, to control and follow-up with other staff). If the females are married then taking care of their children will take time and may not enable them to deliver the work on time. Other interviewees saw that even if females want to work for late hours or on vacations in Jordan, the poor and insecure transportation system would prove to be an obstacle for them to do that. One female financial manager said that:

I was working for late hours (sometimes $10 \mathrm{pm}$ ) and I am single and from an open-minded family, yet I was having conflict with them for this. On the other hand, my relative male colleagues are welcomed to work until late even if their productivity working late is less than mine.

Another female in a high audit position said:

As I am the manager I work frequently for late times and in vacations. I also try to make sure that my female employees go back to home safely, even if they are no later than $9 \mathrm{pm}$.

One male CFO's opinion was that:

Females in accounting - related jobs should not take many vacations, especially in high positions, since there are lots of updates and needs for urgent decisions which could not wait until the manager comes back, or sometimes there is need to call for work on late hours, an issue that is not a problem for male employees but a big problem for female employees. This is exacerbated by, for example, the maternity vacation.

\subsubsection{Effect of Marital Status and Family Responsibilities}

It seems from the findings of the interviews that the factor of marital status and family responsibilities has its effects on the career success of females more than males in Jordan. For example, one male financial manager argued that:

Single males do not concentrate on their jobs until they get engaged or married. To the contrary, females have full concentration on their jobs until they get engaged or married, when most of them leave their jobs although some have good positions.

Another female in a high banking position gave an example:

My female colleague left her good position at a bank because her brothers got a good job opportunity outside Jordan and the whole family will leave Jordan, so she sacrificed her job even though she is single.

This is similar to another reported case when a female external auditor was not given permission by her parents to travel for a new job at another branch of her Big Four audit firm.

A male internal auditor mentioned two examples:

1) I face a lot of situations in Jordan where the females' mentors join them at the job interview.

2) I rejected one female because her mother called me on my phone on the next working day to ask permission for her daughter to leave to take lunch with the family.

Several interviewees argued that such cases will not be seen in developed countries.

Most females leave their jobs because they cannot balance the job-related responsibilities and their home responsibilities, and they therefore give priority to their families, even if these females occupy high positions. They sometimes refuse promotion offers because they know that this will mean travelling more frequently and having more responsibilities. In developed countries, women tend to get married at older ages and have fewer children, facts that limit such issues, compared to the case in Jordan. In addition, males and females in developed 
countries tend to share family responsibilities more than is the case in Jordan, where many responsibilities are assigned to the female. This implies that the Jordanian society is to some extent caring about males more than females and not supporting female workers.

\subsubsection{Mobility}

Generally, most of the interviewees agreed that mobility affects females more than males in Jordan because of the poor and insecure transportation. In developed countries, this is not considered a big issue to the same extent, since transportation is generally safer and works for 24 hours, seven days a week. Actually, one female in a high banking position said:

I rejected a good opportunity with good anticipated experience because the company was located out of Amman, the fact that makes me need to drive about one hour to reach the location using highways, as this is dangerous, especially in Winter and dark. If my car tire needs to be repaired what shall I do?

A male interviewee claimed that even during important meetings a female employee may ask permission to leave even before 15 minutes of the end of that meeting because someone from her family is waiting outside to take her home, an act that absolutely no male will do. Similarly, one female financial manager said that:

Most of my male staff comes to work together in the same cars, especially in winter times, in order to help each other when they face any problem during driving on streets that may be in bad conditions.

Obviously, females cannot do that, and are therefore disadvantaged.

Some managers may see this as a legal way to make females staff quit their jobs because they are signing a contract which includes that the company has the right to make the employee hold different positions in different locations. These managers know that many families will not accept that for their daughters or wives. This implies that employers are sometimes manipulating the regulations and laws for their own benefits.

\subsubsection{Job Description}

All of the interviewees agreed that job descriptions are generally related to the industry itself not to the gender of the employee. However, sometimes even if job description is included in the contract as a package, in the cases where the location of the job is far and there is need to be there late, companies directly ask a male to take this job. If the location is not secure both males and females tend to refuse going there, but the manager has a higher chance of convincing a male to take this task that potentially gives him good experience and may lead to quicker promotion and higher salary, compared to his female colleague.

It is interesting to note that some interviewees said that this case is less frequent in developed countries, given that in many cases asking for the gender of a job applicant is not allowed, and that insisting on such an issue may make the applicant consider suing the company.

\subsection{Effects of Personal Characteristics and Workplace Conditions on Pay and Job Progress}

Some interviewees argued that all personal characteristics and workplace conditions affect the payment level and job progress. This is because males have much more diversified experience that affects the way they deal with their work or communicate with clients. This is in addition to the better professional networking males tend to have that plays a big role in finding new high positions with highly paid salaries for males rather than females.

Other interviewees saw that the evaluation, job progress and payment level depend on the quality of work of that employee (regardless of gender), rather than their experience and qualifications. Some financial managers see that qualification is not the main criterion to evaluate the employee work, but rather the evaluation depends on his/her quality of work.

More than 18 interviewees with high positions and significant experience pointed that females are receiving lower salaries than their male colleagues at the same position and possessing the same experience, because the females in Jordan take their jobs more seriously and find them as a challenge, so they tend to accept any salary just to prove they can handle it in an efficiency way. Other interviewees argued that females do not have the payment negotiation commitment like males, and the employers take this into account when hiring females. Some prefer hiring females although they take several long vacations but their quality of work deserves it.

\subsection{Effects of the Characteristics of the Jordanian Context on Findings, and Whether Jordan Differs from Developed Countries}

This subsection discusses the views of interviewees on the differences between the Jordanian society and those of more-developed countries, and the potential impact this might have on the status of women in accounting-related jobs in Jordan, and how they might differ from men on that. Given the need for international 
experience for the interviewee to be able to comment on this issue, the views reported below are mainly from interviewees with ample international experience (That is, interviewees who worked abroad and/or worked for international companies / international audit firms). As reported earlier, the majority of the sample has such experience. Individual quotes are not emphasised in this section to avoid unnecessary repetition, as most quotes reported earlier apply to some extent to this section.

Several studies discussed how the Jordanian culture plays a role in unequal treatment between males and females in professional life. These studies include Peebles, Darwazeh, Ghosheh and Sabbagh (2007) and Abed and Al-badainah, (2013), which talk about the discrimination in general like putting social obstacles in front of women, the factor that raises the unemployment rate for women, compared to men. Many male mentors encourage their daughters, wives and sisters to work in specific fields, such as education and nursing, but do not prefer them to work as mangers or auditors. Despite the issue of women having resources and being supported by some local laws and regulations, according to the Jordanian culture they generally still follow what their male mentors prefer and do not tend to work as managers.

As for personal characteristics all interviewees except one reported that females in Jordan are generally being brought up as dependable on the males, and this may affect their personality and limit their work success. Most interviewees argued that decisiveness in decision making depends on personality, but some interviewees saw that males are tougher in taking decisions because the society raises men as the ones who give orders, and that men are more confident in making decisions, while women are prone to involving their emotions in the decision making process. According to these interviewees females take tougher decisions in the developed countries than in Jordan, because in the developed countries, females tend not to be raised to accept the orders from their supervisors without discussion. However, some interviewees argued that this mainly applies to junior level jobs, and is likely to be reduced if the woman stays in the profession for longer and is promoted to more senior jobs.

This view about women in accounting-related jobs in Jordan was seen by some interviewees to imply that Jordanian women are generally less likely than men to aspire for better salaries (given women's dependence on men), and that women think longer about changing jobs if they are comfortable with the workplace conditions. This is to the contrary to females in more-developed countries who tend to have a higher degree of responsibility to raise money than the Jordanian females. Also, the issue that Jordanian women tend to marry earlier and have more family responsibilities than their counterparts in more-developed countries might limit their career aspirations.

Findings showed clearly that males have more work experience than females, in terms of number of years and diversity. Males are more exposed to different cultures and work circumstances, and they travel more often than females. This issue is less existent in developed countries because females are more exposed and travel more freely. A similar issue occurs with working for late hours and using public transportation, as a number of interviewees reported that females in accounting-related jobs in Jordan face workplace conditions that do not allow them to work for late, even if they want to do so. The poor public transportation system in Jordan exacerbates this problem. Clearly, more-developed countries have less of these issues compared to Jordan.

In summary, it seems that it can be concluded that there is some level of inequality between females and males in the workplace in Jordan due to several factors, and that these factors may lead to females receiving lower salaries and facing inferior job progress prospects. Compared to the situation in more-developed countries, it can be concluded that the gender inequality gap facing women is even larger in Jordan due to social conservatism factors. This conclusion is also generally supported by a number of international studies. Yeganeh and May (2011) talked about the gap in the work opportunities, qualifications and legalism over 53 countries. They found that the gap is wider in more conservative societies, and that autonomy may lead to gender equality. It is clear that Jordan is more conservative than more-developed countries, and that females in the latter have more autonomy. Volpe and Murphy (2011) attempted to understand why married women choose to leave their jobs. Contrary to findings of this study that women in Jordan leave mainly due to social factors such as effects of males and family responsibilities, they found that married women's career exit decisions are affected by structural constraints shaping their social network, the woman's identity, and the outcomes of exiting. As concerning accounting-related gender studies, it can be seen that a significant number of the studies discussed earlier (see Whiting \& Wright, 2001; Broadbent \& Kirkham, 2008; Komori, 2008; Dambrin \& Lambert, 2012) rarely ever mention social conservatism as a current reason for gender discrimination against women in the workplace, but rather emphasise other factors, such as workplace conditions.

\section{Conclusions}

This study highlighted the differences between females and males in accounting-related jobs in Jordan and 
compared them with the situation in the developed countries. It emphasised the differences between males and females in terms of their personal characteristics and the workplace conditions, and how each of these factors may affect pay level and work progress of both sexes.

In summary, it was found from the interviews that personal characteristics depend on the individual person not on his/her gender. However, the Jordanian culture plays a big role in the issue since females are raised to accept orders and males to give them in most Jordanian families. This form is extended to schools and universities which do not include soft and communication skills in their teaching programs. While both males and females are negatively affected by that, the negative effect is more on females, who already lack personal skills. Educational organisations should teach their students how to be leaders, not to be bosses with a mentality that makes them not accept orders or even hear suggestions from females. According to many interviewees, females are more adaptable to change and committed to quality than males, but males tend to have better leadership and decision making abilities, for reasons related to both their nature and their social upbringing. Males, especially at junior levels, were reported to have clearer career aspirations and willingness to take responsibilities, but there was no clear difference between males and females regarding ability to handle pressure.

As for workplace conditions, it was generally found from the interviews that while both males and females do possess academic, and often professional certificates, males were found to have better experience, due mainly to having more jobs, frequently in different countries, and having better professional networking. Females were found to be generally lacking, compared to males, in terms of their mobility (especially under poor transportation) and their ability to work additional hours (due to carrying most of the burden of family responsibilities). This to some degree affects the job descriptions for jobs occupied by women, as in Jordan there are still many jobs in the accounting area that women do not generally enter or stay in, especially at top levels.

As for the effect of personal characteristics and workplace conditions on the pay levels and job progress prospects of males and females, it can be seen from the interviews that male accountants generally have better qualifications and experience and accept harsher workplace conditions. In addition, the society and culture still favour males for leadership positions and this is likely to lead to better pay and job prospects for males. In summary, it can be argued that there is some level of discrimination against females in the workplace in Jordan due to several factors, and that these factors may lead to females receiving lower salaries and job progress prospects. These factors include that some requested personal characteristics and qualities are generally more available in males than in females given both their nature and their social and cultural upbringing.

Previous studies (such as Fasci \& Valdez, 1998; Whiting \& Wright, 2001; Broadbent \& Kirkham, 2008; Dambrin \& Lambert, 2008; Dambrin \& Lambert, 2012) have shown that discrimination against women in accounting-related jobs is a worldwide phenomenon, while some previous studies (such as Reed et al., 1994 and Wootton \& Spruill, 1994) showed that this phenomenon has persisted for many years. However, it can be argued that this phenomenon in Jordan may have different characteristics. As for personal characteristics, the social and cultural upbringing of females makes them less likely than their counterparts in more developed countries to have leadership and decision making abilities, or have high career aspirations and desire for responsibilities. As for workplace conditions, females in Jordan are less likely than their counterparts in developed countries to possess the needed qualifications and experience, and face some issues in the workplace, such as limited mobility and ability to travel and more family responsibilities. Indeed, Jordanian women are more likely than their counterparts in developed countries to get married early and have more children. This is likely to lead to inequality between women and men in accounting-related jobs in terms of pay and job progress. This discrimination is exacerbated by the lack of sufficient monitoring of these issues and the lack of employee unions and similar organisations that care for sufficient compliance with work laws and non-discrimination in the workplace.

The researchers recommend spreading the awareness among families that females can be seen in high level positions and take the correct decisions in accounting-related professional jobs. This is because if the society is to develop, this starts with the family and how children are raised to have positive personal skills. In addition, given the very poor public transportation system in Jordan, employers in accounting-related jobs should provide secure and good transportation for their employees especially after normal working hours and for women. Another recommendation of this study is that the government should monitor and prosecute the organisations and companies that unfairly discriminate in working conditions against female employees.

\section{References}

Abed, S., \& Al-Badainah, J. (2013). The Impact of auditor's gender on audit fees: Case of Jordanian auditors, International Journal of Business and Management, 8(14), 127-133. 
http://dx.doi.org/10.5539/ijbm.v8n14p127

Ahrens, T., \& Chapman, C. S. (2006). Doing qualitative field research in management accounting: Positioning data to contribute to theory. Accounting, Organizations and Society, 31, 819-841. http://dx.doi.org/10.1016/j.aos.2006.03.007

Ahrens, T., \& Dent, J. (1998). Accounting and organizations: Realizing the richness of field research. Journal of Management Accounting Research, 10, 1-39.

Barker, P. C., \& Monks, K. (1998). Irish women accountants and career progression: A research note. Accounting, Organizations and Society, 23(8), 813-823. http://dx.doi.org/10.1016/S0361-3682(98)00009-9

Bernardi, R. A. (1998). The implications of lifestyle preference on a public accounting career: An exploratory study. Critical Perspectives on Accounting, 9, 335-351. http://dx.doi.org/10.1006/cpac.1997.0190

Brennan, N., \& Nolan, P. (1998). Employment and remuneration of Irish chartered accountants: Evidence of gender differences. European Accounting Review, 7(2), 237-255. http://dx.doi.org/10.1080/096381898336466

Broadbent, J., \& Kirkham, L. (2008). Glass ceilings, glass cliffs or new worlds? Revisiting gender and accounting. Accounting, Auditing and Accountability Journal, 21(4), 465-473. http://dx.doi.org/0.1108/09513570810872888

Collins, K. (1993). Stress and departures from the public accounting professional: A study of gender differences. Accounting Horizons, 7(1), 29-38.

Dambrin, C., \& Lambert, C. (2008). Mothering or auditing: The case of two Big Four in France. Accounting, Auditing and Accountability Journal, 21(4), 474-506. http://dx.doi.org/10.1108/09513570810872897

Dambrin, C., \& Lambert, C. (2012). Who is she and who are we? A reflexive journey in research into the rarity of women in the highest ranks of accountancy. Critical Perspectives on Accounting, 23, 1-16. http://dx.doi.org/10.1016/j.cpa.2011.06.006

Davidson, R. A., \& Dalby, J. T. (1993). Personality profile of female public accountants. Accounting, Auditing and Accountability Journal, 6(2), 81-97. http://dx.doi.org/10.1108/09513579310036396

Eitzen, D. S., Zinn, M. B., \& Smith, K. E. (2010). Social problems (12th ed.). Pearson Education.

Ericksson, P., \& Kovalainen, A. (2008). Qualitative methods in business research. Sage Publications. http://dx.doi.org/10.4135/9780857028044

Fasci, M. A., \& Valdez, J. (1998). A performance contrast of male- and female-owned small accounting practices. Journal of Small Business Management, July, 1-7.

Fogarty, T. (1996). Gender differences in the perception of the work environment within large international $\begin{array}{lllll}\text { accounting firms. Managerial Auditing Journal, 11(2), } & \text { 10 }\end{array}$ http://dx.doi.org/10.1108/02686909610107924

French, S., \& Meredith, V. (1994). Women in public accounting: Growth and advancement. Critical Perspectives on Accounting, 5(3), 227-241. http://dx.doi.org/10.1006/cpac.1994.1013

Glense, C. (2011). Becoming qualitative researchers: An introduction (4th ed.). Pearson Education Inc, Boston, MA, USA.

Komori, K. (2008). Towards the feminization of accounting practice: Lessons from the experiences of Japanese women in the accounting profession. Accounting, Auditing and Accountability Journal, 21(4), 507-538. http://dx.doi.org/10.1108/09513570810872905

Kornberger, M., Carter, C., \& Ross-Smith, A. (2010). Changing gender domination in a Big Four accounting firm: Flexibility, performance and client service in practice. Accounting, Organizations and Society, 35, 775-791. http://dx.doi.org/10.1016/j.aos.2010.09.005

Kumar, K. S. (2010). Gender imbalance in accounting profession: Evidence from Botswana. The IUP Journal of Accounting Research and Audit Practices, 9(4), 42-53.

Lord, B., \& Robb, A. (2010). Women students and staff in accountancy: The Canterbury tales. Accounting History, 15(4), 529-558. http://dx.doi.org/ 10.1177/1032373210372956

Peebles, D., Darwazeh, N., Ghosheh, H., \& Sabbagh, A. (2007). Factors affecting women's participation in the private sector in Jordan. National Center for Human Resources Development, Canadian International 
Development Agency, Canada.

Reed, S. A., Kratchman, S. H., \& Strawser, R. H. (1994). Job satisfaction, organizational commitment and turnover intentions of United States accountants: The impact of locus of control and gender. Accounting, Auditing and Accountability Journal, 7(1), 31-58. http://dx.doi.org/10.1108/09513579410050371

Vaivio, J. (2008). Qualitative management accounting research: Rationale, pitfalls and potential. Qualitative Research in Accounting and Management, 5(1), 64-86. http://dx.doi.org/10.1108/11766090810856787

Volpe, E. H., \& Murphy, W. M. (2011). Married professional women's career exit: Integrating identity and social networks. Gender in Management: An International Journal, 26, 57-83. http://dx.doi.org/10.1108/17542411111109318

Whiting, R. H., \& Wright, C. (2001). Explaining gender inequity in the New Zealand accounting profession. British Accounting Review, 33, 191-222. http://dx.doi.org/10.1006/bare.2001.0161

Wootton, C. W., \& Spruill, W. G. (1994). The role of women in major public accounting firms in the United States during World War II. Business and Economic History, 23(1), 241-252.

Yeganeh, H., \& May, D. (2011). Cultural values and gender gap: A cross-national analysis. Gender in Management: An International Journal, 26(2), 106-121. http://dx.doi.org/0.1108/17542411111116536

Zubaidi, F. R., Al-sammerai, N. S. M., \& Ahmad, F. (2011). An overview on Women's leadership issues in Jordan. Journal of Politics and Law, 4(2), 67-73. http://dx.doi.org/10.5539/jpl.v4n2p67

\section{Appendix}

Appendix A. Interview questions

Differences between male and female accountants in Jordan regarding personal characteristics:

a) May you compare between male and female accountants and auditors in Jordan regarding their decisiveness in decision making? Compared to the situation in developed countries, does the Jordanian environment and culture affect your views regarding women in accounting positions.

b) May you compare between male and female accountants and auditors in Jordan regarding their leadership ability? Compared to the situation in developed countries, does the Jordanian environment and culture affect your views regarding women in accounting positions.

c) May you compare between male and female accountants and auditors in Jordan regarding their career aspirations and desire for responsibility? Compared to the situation in developed countries, does the Jordanian environment and culture affect your views regarding women in accounting positions.

d) May you compare between male and female accountants and auditors in Jordan regarding their ability to handle pressure and high volume workloads? Compared to the situation in developed countries, does the Jordanian environment and culture affect your views regarding women in accounting positions.

e) May you compare between male and female accountants and auditors in Jordan regarding their adaptation to change? Compared to the situation in developed countries, does the Jordanian environment and culture affect your views regarding women in accounting positions.

f) May you compare between male and female accountants and auditors in Jordan regarding their commitment to quality? Compared to the situation in developed countries, does the Jordanian environment and culture affect your views regarding women in accounting positions.

Differences between male and female accountants in Jordan regarding workplace conditions:

a) May you compare between male and female accountants and auditors in Jordan regarding their competitiveness in qualifications? Compared to the situation in developed countries, does the Jordanian environment and culture affect your views regarding women in accounting positions.

b) May you compare between male and female accountants and auditors in Jordan regarding their competitiveness in work experience? Compared to the situation in developed countries, does the Jordanian environment and culture affect your views regarding women in accounting positions.

c) May you compare between male and female accountants and auditors in Jordan regarding their number of working hours (including working during vacation)? Compared to the situation in developed countries, does the Jordanian environment and culture affect your views regarding women in accounting positions. 
d) May you compare between male and female accountants and auditors in Jordan regarding the effect of marital status and family responsibilities? Compared to the situation in developed countries, does the Jordanian environment and culture affect your views regarding women in accounting positions.

e) May you compare between male and female accountants and auditors in Jordan regarding their mobility? Compared to the situation in developed countries, does the Jordanian environment and culture affect your views regarding women in accounting positions.

f) May you compare between male and female accountants and auditors in Jordan regarding their job descriptions? Compared to the situation in developed countries, does the Jordanian environment and culture affect your views regarding women in accounting positions.

Differences between male and female accountants in terms of pay and job progress:

a) May you give us your views on the likely effect of the personal characteristics of male and female accountants and auditors in Jordan on their pay levels? Compared to the situation in developed countries, does the Jordanian environment and culture affect your views regarding women in accounting positions.

b) May you give us your views on the likely effect of the personal characteristics of male and female accountants and auditors in Jordan on their job progress? Compared to the situation in developed countries, does the Jordanian environment and culture affect your views regarding women in accounting positions

c) May you give us your views on the likely effect of the work conditions of male and female accountants and auditors in Jordan on their pay levels? Compared to the situation in developed countries, does the Jordanian environment and culture affect your views regarding women in accounting positions

d) May you give us your views on the likely effect of the work conditions of male and female accountants and auditors in Jordan on their job progress? Compared to the situation in developed countries, does the Jordanian environment and culture affect your views regarding women in accounting positions

\section{Copyrights}

Copyright for this article is retained by the author(s), with first publication rights granted to the journal.

This is an open-access article distributed under the terms and conditions of the Creative Commons Attribution license (http://creativecommons.org/licenses/by/3.0/). 